\title{
PREVALENCE OF FUNGAL IN OPPORTUNISTIC INFECTION HIV TYPE-1 IN SUBURBAN, KADAPA
}

\author{
GUNDALA OBULESU ${ }^{1 *}$, HANUMANTHAPP AR ${ }^{2}$, PRABAKAR REDDY E ${ }^{3}$
}

${ }^{1}$ Bharath University, Chennai, Tamil Nadu, India. ${ }^{2} \mathrm{JJM}$ Medical College, Davangere, Karnataka, India. ${ }^{3}$ Department of Biochemistry, Sri Lakshmi Narayana Institute of Medical Sciences, Puducherry, India. Email: obulesu100@gmail.com

Received: 26 April 2017, Revised and Accepted: 17 May 2017

\section{ABSTRACT}

Objective: Isolate fungal element causing in opportunistic infection of human immunodeficiency virus and correlated with CD4 cell counts.

Methods: Different samples are used and media: Sabouraud dextrose agar, using mycological methods such as potassium hydroxide, lactophenol cotton blue mount, India ink preparation, and Gram-staining.

Results: Both bacterial and fungal isolates were obtained from 8 cases. Pneumococci and Candida spp. were observed in 3 cases followed by Staphylococcus aureus and Aspergillus in 2 cases, Klebsiella pneumoniae and Geotrichum spp., Pneumococci and Penicillium spp., and Acinetobacter baumannii, and Cryptococcus spp. from 1 case each. Only fungal isolates were obtained from 6 cases of sputum samples. Candida spp. (50\%) were predominant fungal isolate followed by Aspergillus spp. (33.33\%) and Cryptococcus spp. (16.66\%). Cryptococcus spp. was the predominant fungal isolate (66.6\%) followed by Candida pseudotropicalis (Kefyr) in 16.66\% (1/6) and Acinetobacter spp. was isolated from 16.66 \% (1/6).

Conclusion: Respiratory infections were the predominant manifestations comprising chronic bronchitis, pneumonia, chronic obstructive pulmonary disease, and chronic cough. 66 individuals were with respiratory symptoms, of them 28 individuals had CD 4 count $50-200 / \mathrm{mm}^{3}, 22$ had CD $4<50 / \mathrm{mm}^{3}$.

Keywords: Acquired immune deficiency syndrome, Human immunodeficiency virus, CD4.

(C) 2017 The Authors. Published by Innovare Academic Sciences Pvt Ltd. This is an open access article under the CC BY license (http://creativecommons. org/licenses/by/4. 0/) DOI: http://dx.doi.org/10.22159/ajpcr.2017.v10i6.19404

\section{INTRODUCTION}

The acquired immune deficiency syndrome (AIDS) is a dreadful disease that kills productive age group of our society globally. The human immunodeficiency virus (HIV) suppresses the immunity by destroying a certain type of blood cells, known as CD 4 cells, which helps the body to fight the entry of infections [1]. The immunocompromised status of any human being invites all possible opportunistic infections, and if not properly controlled, it results in death. Since the beginning of the epidemic, more than 70 million people have been infected with the HIV [2]. Clinical manifestations in HIV infections are primarily not due to viral cytopathology but are secondary to failure of immune response. Development of microbial resistance, the prospectus to manage the public health crisis has worsened drastically. Several infective organisms responsible for opportunistic infections differ in characteristics from that of conventional communicable disease and are mainly low or non-virulent; hence, these could be non-pathogenic in individuals with intact immune system (Candida albicans) or known pathogens presenting in a different way than usual in immune competent individuals (Cryptococcus neoformans) or in the form of increased virulence, recurrence, multidrug resistance (mycobacterium tuberculosis), or atypical presentation (dermatophytosis) [3].

\section{METHODS}

The blood and other clinical samples such as corneal swab, cerebrospinal fluid (CSF), faeces, NA and wound pus, oral swab, skin scrapings, sputum, throat swab, urine, and vaginal swabs were collected from the Fatima Institute of Medical Sciences, Kadapa, Andhra Pradesh, for the diagnosis of HIV and AIDS-related opportunistic infections 2014-2016. Microbiological techniques used for isolation of opportunistic infection. Initially, the following details of sociodemographic features, physical, and Hi-media chemicals/reagents were used for the microbiological culture and biochemical characterization of opportunistic pathogens. The following necessary tests were carried out with appropriate procedures for the diagnosis and confirmation of HIV. CD4 count, microbiological techniques were followed for the detection of opportunistic pathogens. Samples, blood, urine, sputum, and virginal swab collected by sterile standard procedure depending on sample, potassium hydroxide $(\mathrm{KOH})$ mount for skin scrapings.

The infected area of the skin lesions was cleaned with surgical spirit and scraped with the edge of the clean slide. The scrapings were collected in a sterile petri plate. Sample $10 \%$ of $\mathrm{KOH}$ solution and gently passed over the Bunsen flame for the digestion of skin keratin material. Then, the slide was examined under light microscope for the presence of fungal hyphae and spores [4].

\section{Lactophenol cotton blue (LPCB) mount}

The LPCB mount was mainly carried out for the diagnosis of morphological characterization of fungi isolated from cultures. The isolated fungal colonies were gently teased by a thin cover slip, and it was placed in a new glass slide containing l-2 drops of LPCB. The content was mounted with a cover slip and examined carefully under a light microscope for the detection of fungal morphology and conidiophores [5].

\section{India ink preparation}

The India ink preparation was mainly used for the diagnosis of encapsulated yeasts in CSF sample sediments. One or two drops of India ink were added over the CSF sediment in a new glass slide. It was covered with a cover slip without air bubbles. The slide was carefully examined under light microscope for the presence of encapsulated yeasts in singles and with budding [6].

\section{Gram-staining}

The Gram-staining was used for primary clinical and detection of the organism from culture. The smear was prepared in clean, grease, and scratch-free new slides. The smear was air-dried and heat fixed gently by passing over the Bunsen flame. 
The smear was well covered with crystal violet and allowed to act for 2 minutes and then, washed with running tap water. Then, the smear was covered with grams iodine for 1 minute and washed with running tap water. The smear was decolorized with acetone and washed with running tap water. Finally, stained with diluted corbol - fuchsin 1:10 ratio) for 1 minute and washed with running tap water. The slide was blot dried and examined under $\times 100$ objective of light microscope [7].

Penicillium spp. was rapid growing blue-green filamentous fungi with rugosities and microscopically there was brush-like branching of conidiophores bearing long chains of small, spherical conidia borne from flask shaped blunt sterigtmata [8].

Aspergillus spp. were identified by rapidly growing filamentous fungi exhibiting various colors from blue to green to yellow due to dense production of pigmented spores, and microscopically by chains of oval to spherical conidia borne from the tip of one or two rows of sterigmata arranged radially over the surface of the swollen tip of conidiophore called vesicle. Aspergillus fumigatus colony had a shade of smoky green and reverse was white to tan. The conidiophores were smooth, uniseriate phialides covering upper half of vesicle. Conidia were borne in chains from tips of sterigmata. Aspergillus flavus colony was yellow to green and reverse golden to red-brown. Conidiophores were pitted and spiny; biseriate phialides. Conidia covered the vesicle completely as a globular mass. Aspergillus niger colony had a jet black, granular surface due to dense proliferation of black spores. Reverse was light tan to gray. Conidiophores were of variable length biseriate phialides covered the entire vesicle, conidia were jet black covering the entire surface and obscuring the vesicle [9].

Cryptococcus spp. were identified by budding yeast cells on wet mount and $\mathrm{KOH}$ preparation and Gram-positive budding yeast cells on Gramstain directly from the sample. Colony morphology yeast like highly mucoid on sabrose dextrose agar. Spherical single or multiple budding, thick-walled, yeast-like organisms 2-15 mm in diameter, surrounded by a wide refractile clear halo was observed on capsular staining (Congo red preparation), urease positive, and growth on blood agar at $37^{\circ} \mathrm{C}[10]$.

Trichophyton rubrum was identified by white, velvety to fluffy occasionally powdery to granular with diffuse wine red-colored pigmentation on the reverse and microscopically, scanty numerous pyriform microconidia borne singly along the hyphae and pencilshaped macro conidia and urease test negative [11].

\section{RESULTS}

Both bacterial and fungal isolates were obtained from 8 cases. Pneumococci and Candida spp. were observed in 3 cases followed by S. aureus and Aspergillus in 2 cases, K. pneumoniae and Geotrichum spp., Pneumococci and Penicilliumspp and A. baumanii and Cryptococcus spp. from 1 case each (Table 1 ).

Only fungal isolates were obtained from 6 cases of sputum samples. Candida spp. (50\%) were the predominant fungal isolate followed by Aspergillusspp (33.33\%) and Cryptococcus spp. (16.66\%) (Table 2).

C. albicans was the predominant isolate $(69.23 \%)$ followed by non-C. albicans $30.76 \%(8 / 26)$. Of 8 non-C. albicans 4 were $C$. tropicalis, 2 were Candida Kefyr (Pseudotropicalis) and 2 were Candida parapsilosis (Table 3).

2 cases were culture positive and remaining 8 cases were culture negative. T. rubrum was isolated from 2 cases (Table 4).

The above Table 5 shows that fungal isolates were obtained from 5 cases and bacterial isolate from 1 case. Thus, the total culture positivity was $46.15 \%(6 / 13)$ and 7 cases were culture negative (53.84\%).

Cryptococcus spp. was the predominant fungal isolate (66.6\%) followed by C. pseudotropicalis (Kefyr) in $16.66 \%(1 / 6)$ and Acinetobacter spp. was isolated from $16.66 \%(1 / 6)$ (Table 6).

\section{DISCUSSION}

Table 1 shows mixed bacterial and fungal isolates from sputum samples. In the present study, $14.81 \%$ ( 8 cases) showed mixture of bacterial and fungal isolates, of them 3 cases showed Pneumococci with C. albicans and 2 cases $S$. aureus with Aspergillus spp. [12]. Hyderabad reported 5 cases with mixture of bacteria and fungi isolated from sputum samples.

Table 2 shows fungal isolates from sputum samples. In the present study, $11.11 \%$ (6 cases) were fungal isolates. Although fungal isolates are less common than bacterial isolates, serious fungal infections occur in the immune compromised patients both as a new infection and as reactivation of latent disease.

C. albicans was isolated from 3 cases, to rule out the possibility of oropharyngeal colonization a common feature among HIV reactives, those cases with plenty of pseudohyphae on smear examination were considered as significant pathogens.

Table 1: Mixed bacterial and fungal isolates from sputum samples

\begin{tabular}{llll}
\hline S. No. & Bacterial isolates & Fungal isolates & n (\%) \\
\hline 1. & Pneumococci & Candida spp. & $3(37.5)$ \\
2. & S. aureus & Aspergillus spp. & $2(25)$ \\
3. & K. pneumoniae & Geotrichum spp. & $1(12.5)$ \\
4. & Pneumococci & Penicillium spp. & $1(12.5)$ \\
5. & A. baumanii & Cryptococcus spp. & $1(12.5)$ \\
\hline
\end{tabular}

Table 2: Fungal isolates from sputum samples $(n=6)$

\begin{tabular}{lll}
\hline S. No. & Isolates & n (\%) \\
\hline 1. & Candida spp. & $350)$ \\
2. & Aspergillus spp. & $2(33.33)$ \\
3. & Cryptococcus spp. & $1(16.66)$ \\
\hline
\end{tabular}

Table 3: Swabs from oral lesions: Isolates from oral lesions $(n=26)$

\begin{tabular}{lll}
\hline S. No. & Isolates & n (\%) \\
\hline 1. & C. albicans & $18(69.23)$ \\
2. & non-C. albicans & $8(30.76)$ \\
\hline
\end{tabular}

Table 4: Skin scrapings: Culture positivity for skin scrapings $(n=10)$

\begin{tabular}{lll}
\hline Number of cases & Culture positive & Culture negative \\
\hline 10 & $2(20 \%)$ & $(80 \%)$ \\
\hline
\end{tabular}

Table 5: CSF: Culture positivity from CSF samples $(n=13)$

\begin{tabular}{ll}
\hline Type of isolates & $\mathbf{n}(\mathbf{\% )}$ \\
\hline No of bacterial isolates & $1(7.69)$ \\
No of fungal isolates & $5(38.46)$ \\
No of culture negative cases & $7(53.84)$ \\
\hline
\end{tabular}

Table 6: Organisms isolated from CSF $(n=6)$

\begin{tabular}{lll}
\hline S. No. & Organisms & n (\%) \\
\hline 1. & Cryptococcus spp. & $4(66.66)$ \\
2. & Candida spp. & $1(16.66)$ \\
3. & A. baumannii & $1(16.66)$ \\
\hline
\end{tabular}


Aspergillus spp. were isolated from two cases and Cryptococcus spp. from 1 case [12]. From Hyderabad reported 9 cases with fungal etiology, of them 6 cases were $C$. albicans followed by 2 cases $C$. neoformans and one case A. niger.

As shown in Table 3, swabs from oral lesions showed $81.25 \%$ culture positivity. $69.23 \%(18 / 26)$ cases were due to C. albicans and $30.76 \%$ were due to non-C. albicans spp. (C. tropicalis, C. Kefyr and C. parapsilosis) [13] from Punjab who reported $62.5 \%$ cases due to C. albicans and $37.5 \%$ due to non-C. albicans [14]. Aurangabad reported $82.05 \%$ C. albicans and $17.9 \%$ non-C. albicans.

Table 4 shows isolates from skin scrapings of tinea cases. Of 10 cases, 2 cases (20\%) showed culture positivity. T. rubrum was isolated [15].

Table 5 shows culture positivity from CSF samples. Of 13 cases, 6 cases $(46.15 \%)$ were culture positive, of them 5 cases $(38.46 \%)$ were due to fungal isolates and 1 case $(7.69 \%)$ was due to bacterial isolate (A. baumannii) [16].

Table 6 shows fungal isolates from CSF samples, fungal isolates were common than bacterial isolates in CSF samples. Among fungal isolates Cryptococcus spp. was the predominant isolate (4/5) [17]. Cryptococcus meningitis is an emerging opportunistic infection among HIV infected patients. C. Kefyr was the other fungal isolate in the present study) [18-20].

\section{CONCLUSION}

Control group of HIV-seronegative persons with similar symptomatology were also studied for the presence of various pathogens. The most common clinical presentation observed in HIV-seropositive individuals were respiratory infections followed by candidiasis of various sites (oropharyngeal, esophageal, and vaginal), skin infections, chronic diarrhea, chronic fever, tuberculosis cases under treatment, and CNS manifestations. Respiratory infections were the predominant manifestations comprising chronic bronchitis, pneumonia, chronic obstructive pulmonary disease, and chronic cough. 66 individuals were with respiratory symptoms, of them 28 individuals had CD4 count $50-200 / \mathrm{mm}^{3}, 22$ had $\mathrm{CD} 4<50 / \mathrm{mm}^{3}$. From respiratory tract infection, both bacterial and fungal agents were isolated opportunistic infection with fungi are very common in HIV-seropositive individuals particularly of Stage III and IV. Oropharyngeal, esophageal candidiasis and scabies were observed with CD 4 counts $<50 / \mathrm{mm}^{3}$. Respiratory tract infections and CNS infections were common with CD4 counts $50-200 / \mathrm{mm}^{3}$. Prompt identification and treatment of opportunistic infections will contribute to decreased morbidity and mortality.

\section{REFERENCES}

1. Brooks GF, Carroll KC, Butel JS. Jawetz, melnick and adelberg. Review of Medical Microbiology. $22^{\text {nd }}$ ed. Ch. 44. New York: McGraw Hill Professional; 2001. p. 521.

2. AIDS Epidemic Update-Joint United Nations Programme on HIV/AIDS (UNAIDS) and World Health Organization (WHO) "UNAIDS/09.36E/ JC1700E, November; 2015. p. 7

3. Ananthanarayana R, Paniker CK. Human immunodeficiency virus: AIDS. Text Book of Microbiology. $7^{\text {th }}$ ed. Ch. 62. Madras: Orient Long Man Publications; 2005. p. 592.

4. Arora A. Medical Microbiology. $1^{\text {st }}$ ed. London: Academic Press; 2014. p. 42.

5. Mackie JT. Mackie and McCartney: Practical Medical Microbiology. 11 thed. New Delhi: Elsevier; 2006. p. 126

6. Mackie JT. Mackie and McCartney: Practical Medical Microbiology. $11^{\text {the }}$. New Delhi: Elsevier; 2006. p. 380

7. Mackie JT. Mackie and McCartney: Practical Medical Microbiology. $11^{\text {th }}$ ed. New Delhi: Elsevier; 2006. p. 169.

8. Mackie JT. Mackie and McCartney: Practical Medical Microbiology.

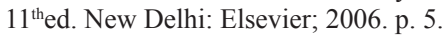

9. Arora R. Medical Mycology. $1^{\text {st }}$ ed. Philadelphia, PA: Lea and Febiger; 2014. p. 122

10. Arora R. Medical Mycology. $1^{\text {ste }}$. Philadelphia, PA: Lea and Febiger; 2014. p. 128-129.

11. Arora R. Medical Mycology. $1^{\text {ste }}$. Philadelphia, PA: Lea and Febiger; 2014. p. 114-1115.

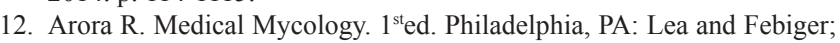
2014. p. 43-4.

13. Shailaja VV, Pai LA, Mathur DR, Lakshmi V. Prevalence of bacterial and fungal agents causing lower respiratory tract infections in patients with human immunodeficiency virus infection. Indian J Med Microbiol 2004;22(1):28-33

14. Aggarwal A, Arora U, Bajaj R. Clinico-microbiological study in HIV seropositive patients. J Indian Acad Clin Med 2005;6(2):142-5.

15. Baradkar VP, Karyakarte RP. Isolation and characterization of Candida species in AIDS. Indian J Med Microbiol 1999;17(1):42-4.

16. Di Silverio A, Brazzelli V. Prevalence of dermatophytes and yeasts (Candida Spp., Malassezia furfur) in HIV patients. Mycopathologia 2004;114:103-7.

17. Arora A. Medical Microbiology. $1^{\text {st }}$ ed. UK: Oxford University Press; 2014.p. 111.

18. Currie BP, Casadevall A. Estimation of the prevalence of cryptococcal infection among patients infected with the HIV in New York city. Clinical Infection 1994;9(6):1029-33.

19. Yehia AG. Treatment of tenia versicolor caused by Malassezia furfur with dill seed extract. Int J Pharm Pharm Sci 2015;7(2):1-7.

20. Medeios CS. Activity anti-C, Tropicalis and effect of the combination of(s)-(s) citronellal with four antifungal applied in vulvoveginal candidiasis. Int J Pharm Pharm Sci 2016;8(8):347-51. 